\title{
Introduction: historical perspectives on pedestrians and the city
}

Colin Pooley, Martin Emanuel, Tiina Männistö-Funk and Peter Norton.

Corresponding author:

Professor Colin Pooley

Lancaster Environment Centre

Lancaster University

Lancaster

LA1 4YQ

c.pooley@lancaster.ac.uk

(See individual papers for other affiliations)

\section{Abstract}

Walking is a neglected topic in the history of transport and mobility in cities. The four essays in this special section demonstrate the importance of travel on foot in nineteenth- and twentieth-century cities in four different countries, and reveal the ways in which pedestrian mobility has persisted despite the development of a car-dominated society. Together they provide important new evidence on a neglected topic and hopefully pave the way for further research on this theme.

Key words: Walking, pedestrianism, cities, mobility

Running head: Pedestrians and the city

Word length: 3887 


\section{Introduction: historical perspectives on pedestrians and the city}

The ability to move easily from place to place is a central feature of everyday life in both rural and urban areas, but the shorter distances to many services combined with denser public transport networks mean that urban living can be more attractive than the countryside where journeys may be more difficult and time-consuming. Most large urban areas developed extensive public transport networks from the late-nineteenth century in the form of bus, tram and trolley bus routes, and railways (both underground and above ground). These networks allowed those urban residents who could access public transport to move easily around the city, and for some enabled a move to a developing suburban location. ${ }^{1}$ At the same time urban road networks were expanded and reconfigured to accommodate the increased volume and diversity of road users that inhabited city streets. In the first half of the twentieth century horse-drawn vehicles, bicycles, motor bikes, cars, vans, trucks and buses all competed for limited road space, but with motorised vehicles becoming increasingly dominant this was often to the detriment of other road users. ${ }^{2}$ Pedestrians and cyclists were especially adversely affected and, while cyclists were at least considered by many as legitimate road users with some limited attempts to plan urban road systems to accommodate bicycles, ${ }^{3}$ pedestrians became almost invisible within the transport planning system. By the mid-nineteenth century most urban streets had pavements and little consideration was given to making further provision for easy and unimpeded pedestrian travel within urban areas. Indeed, in many instances changes to road junctions and traffic signals were designed to restrict pedestrian movement in order

${ }^{1}$. See for example H. J. Dyos, and D. Aldcroft, British Transport: an Economic Survey from the Seventeenth century to the Twentieth (Leicester, 1969); A. Jackson, Semi-detached London: Suburban Development, Life and Transport, 1900-39 (London, 1973).

2. P. Norton, Fighting Traffic: the Dawn of the Motor Age in the American City (Boston, MA, 2011);

G. Mom, Atlantic Automobilism: Emergence and Persistence of the Car, 1895-1940 (New York, 2014).

3 . D. Horton, P. Rosen and P. Cox (eds), Cycling and Society (Farnham, 2007); R. Oldenziel and A. A. de la Bruhèze, 'Contested spaces: Bicycle lanes in urban Europe, 1900-1995', Transfers, 1 (2011), 2949; M. Emanuel, "Constructing the Cyclist: Ideology and Representations in Urban Traffic Planning in Stockholm, 1930-70." Journal of Transport History 33, no. 1 (2011): 67-91; R. Oldenziel, M. Emanuel, A. A. de la Bruheze, and F. Veraart, Cycling Cities: The European Experience: Hundred Years of Policy and Practice (Eindhoven, 2016). 
to facilitate the smoother flow of motorised traffic. ${ }^{4}$ However, despite these trends people continued to walk for many everyday journeys, and travel on foot commonly formed a part of most multi-mode trips in urban areas: for instance walking from home to a bus or tram stop, or to a railway station. Indeed, we argue that it is the very normality of walking that has in part led to its invisibility in urban transport planning. Because travel on foot has not required a special technology it has not been viewed as a form of transport, and thus it has been excluded from transport planning. It is its simplicity and ubiquity that has led to its neglect. ${ }^{5}$ For instance, in the UK the Department for Transport (and its predecessors) have rarely explicitly considered walking as a form of transport, and where it has more recently been considered it is linked with cycling even though these are two very different activities that make separate demands on urban space. Much the same was true in Sweden although more recently some policy documents have made the case for considering walking as a distinct travel mode.

The pedestrian has not only been largely excluded from urban transport planning, but also everyday utility walking has been relatively neglected in academic research. Transport historians have for the most part followed the same path as transport planners. Legs and feet have not been viewed as forms of transport and thus rarely get more than a passing mention in most studies of transport history. For instance, in the last 20 years the Journal of Transport History has published only four papers in which the terms walking or pedestrians appeared in the title or abstract of the paper, although walking is likely to have received passing mentions in other papers where the main focus was not on pedestrian travel. ${ }^{6}$ Academic research on walking has, instead, tended to focus on the

${ }^{4}$. See for example ; P. Norton, 'Street rivals: Jaywalking and the invention of the motor age street', Technology and Culture, 48 (2007), 331-359; B. Schmucki, 'Against "the eviction of the pedestrian" The Pedestrians' Association and walking practices in urban Britain after World War II.' Radical History Review, 2012 (2012), 113-138; D. Rooney 'Keeping pedestrians in their place. Technologies of segregation in East London', in P G Mackintosh, R. Dennis and D Holdsworth (eds.), Architectures of Hurry - Mobilities, Cities and Modernity (Abingdon, 2018), 120-136;

${ }^{5}$. For further discussion of this theme see: C. Pooley with T. Jones, M. Tight, D. Horton, G. Scheldeman, C. Mullen, A. Jopson and E. Strano, Promoting walking and Cycling: new Perspectives on Sustainable Travel (Bristol, 2013); C. Pooley, D. Horton, G. Scheldeman, C. Mullen, T. Jones and M. Tight, "'You feel unusual walking": the invisible presence of walking in English cities', Journal of Transport and Health 1 (2014), 260-66.

${ }^{6}$. Papers with a specific focus on walking also appear rarely in Urban History. Notable exceptions are: P. Andersson, "'Bustling, crowding, and pushing": pickpockets and the nineteenth-century street 
more unusual, extreme and performative aspects of walking such as hill and mountain walking in challenging environments, ${ }^{7}$ and on the role of the flâneur in urban life where the purpose of walking is assumed to be related to display and visibility, ${ }^{8}$ rather than viewing walking as a simple, cheap and convenient way of travelling from one place to another: a form of travel that for many people has been the only viable option in much of the past. Walking has also been studied to some extent in the context of research on leisure and, increasingly, with regard to the health benefits of physical exercise and concerns about obesity. ${ }^{9}$ This reflects increased awareness of the ways in which transport, health and social policy are interrelated, with the rise of automobility and the dominance of motorised transport contributing to the development of what some have termed an obesogenic environment in the late-twentieth century. ${ }^{10}$ In some accounts walking has also been viewed as risky, especially for women, creating the impression that travel on foot is not only unusual but also is

crowd', Urban History, 41(2014), 291-310; M. Law, 'Speed and blood on the bypass: the new automobilities of inter-war London,' Urban History, 39 (2012), 490-509; P. Jackson, 'Parading in public: patrician women and sumptuary law in Renaissance Siena', Urban History, 37 (2010), 452463.

7 . For instance H. Lorimer and K. Lund, 'Performing facts: finding a way over Scotland's mountains', The Sociological Review, 51 (2003), 130-144; K. Lund, 'Seeing in motion and the touching eye: walking over Scotland's mountains', Etnofoor, 18 (2005), 27-42.

8 . C. Jenks, 'Watching your step: the history and practice of the flâneur', in C. Jenks (ed.), Visual Culture (London, 1995), 142-160; T. Cresswell and P. Merriman (eds.), Geographies of Mobilities: Practices, Spaces, Subjects (Farnham, 2011); J. Guldi, 'The history of walking and the digital turn: stride and lounge in London, 1808-1851', The Journal of Modern History, 84 (2012), 116-144.

9 . D. King, and S. Jacobson, 2017. 'What is driving obesity? A review on the connections between obesity and motorized transportation', Current Obesity Reports, 6 (2017), 3-9; E. Ussery, S. Carlson, G. Whitfield, K. Watson, D. Berrigan and J. Fulton, 'Transportation and leisure walking among US adults: trends in reported prevalence and volume, National Health Interview Survey 2005-2015', American Journal of Preventive Medicine, 55 (2018), 533-540.

10 . J. Urry, 'The "system" of automobility', Theory, Culture \& Society, 21 (2004), 25-39; T. Townshend and A. Lake, 'Obesogenic environments: current evidence of the built and food environments', Perspectives in Public Health, 137 (2017), 38-44; R. Colls and B. Evans, 'Making space for fat bodies? A critical account of 'the obesogenic environment', Progress in Human Geography, 38 (2014), 733-753. 
potentially dangerous. ${ }^{11}$ This brief review of the historiography of walking demonstrates the neglect of utility (or everyday) walking in the academic literature, and highlights the ways in which -as in most past transport planning ${ }^{12}$ - the pedestrian is not someone to be given serious consideration in the context of transport history. The four articles that follow this introduction provide more extensive historiographical context in relation to the specific case studies presented.

A focus on the role and experiences of the pedestrian can also provide a distinctive and instructive approach to urban history. Whereas much research on the history of towns focuses on the built environment, urban governance and civil society, examination of the view from the street can provide a different perspective. The papers in this collection begin to ask questions such as who was on the street at different times of day and why were they there; how did pedestrians negotiate the urban environment and interact with other modes of movement; how did pedestrians mix with each other to form a community of the street; and what barriers were encountered when walking in the city at different times and locations? Examination of pedestrian practices can provide a distinctive view of the city from those who used the streets to go about their daily lives. The task of recovering pedestrian histories is not easy as those who walked through the city rarely appear in the archival record. Where pedestrians do appear they are often portrayed as flows of sometimes transgressive humanity that need to be managed in some way to avoid conflict with other road users, both to maintain traffic flows and ensure pedestrian safety. The views and experiences of those who actually walked are rarely represented. There has been a recent increase in contemporary research on walking and street practices, often carried out through a combination of in-depth interviews, accompanied journeys and video diaries, with much focus on the development of methods and technologies that facilitate mobile methodologies. ${ }^{13}$ The historian cannot speak to research subjects, but we can try to mirror contemporary methodologies by searching the archives for individual accounts and images of pedestrian travel. These may occur in diaries and other forms of life writing, through photographic collections amassed for entirely different purposes, or by simply looking anew

${ }^{11}$. R. Law, 'Beyond "women and transport": towards new geographies of gender and daily mobility', Progress in Human Geography, 23 (1999), 567-588; B. Schmucki, “'If I walked on my own at night I stuck to well-lit areas." Gendered spaces and urban transport in 20th century Britain', Research in Transportation Economics, 34 (2012), 74-85.

${ }^{12}$. Though this is beginning to change in the context of debates about 'liveable cities'. See for example: http://liveablecities.org.uk/.

${ }^{13}$. B. Fincham, M. McGuinness and L. Murray (eds.), Mobile Methodologies (Basinstoke , 2009); M. Büscher, J. Urry and K. Witchger (eds.), Mobile Methods (Abingdon, 2010); P. Merriman, 'Rethinking mobile methods', Mobilities, 9 (2014), 167-187. 
at archival sources that are more usually used for other purposes. The essays in this collection adopt a variety of these methodologies to investigate the pedestrian in the city. Analysis of walking also requires consideration of other modes of transport as the pedestrian constantly has to interact with other more powerful road users. Thus not only is there need for time-consuming research to tease information on pedestrians from the archives, but also it is necessary to engage fully with research on all the other modes of transport that the pedestrian interacted with on the street. Studying pedestrian practices can be difficult and time-consuming but also rewarding if our aim is to understand urban mundane practices and everyday life.

From a global perspective four main factors usually influence the prominence (or otherwise) of walking as a form or everyday travel. First, lack of resources to afford other forms of transport has been a key constraint both in the past and the present: in many societies it has been assumed that walking is undertaken by poor people and this has affected popular perceptions of pedestrianism. Second and closely interlinked with the above, the extent to which people walk on an everyday basis has depended on the availability of alternative means of transport: in times and places where road and rail infrastructures were limited and/or prior to the development of motorised forms of transport, walking was the main form of transport available to most people. Third, even in places and time periods where multiple forms of transport are readily available they may not be equally accessible to all groups within society. Women, children and those with ill health or other impairments have often been excluded from the fastest and most convenient forms of transport: for instance, throughout the history of the motor car, men have been the majority of drivers, the motor car is the only means of transport that excludes the young and those with health conditions (such as poor eyesight) that limit their ability to drive, and public transport has not always been easily accessible for those with restricted mobility. Fourth, although in the past walking was probably equally common in both rural and urban areas today walking is more prevalent in urban areas in most countries in the world. This is partly a consequence of shorter travel distances and better public transport systems which encourage walking as part of a multi-mode trip, but it also reflects the mostly younger age structure of large urban areas compared to most rural locations. ${ }^{14}$ In the

\footnotetext{
${ }^{14}$. For discussions of some of these issues see for instance: J. Whitelegg, and N. Williams, 'Nonmotorised transport and sustainable development: evidence from Calcutta', Local Environment, 5
} (2000), 7-18;

G. Porter, 'Living in a walking world: rural mobility and social equity issues in sub-Saharan Africa', World Development, 30 (2002), 285-300; Land Transport Authority, 'Passenger transport mode shares in world cities', Journeys 12 (2014), 54-64; Pooley et al. Promoting Walking and Cycling, 17- 
twentieth century lack of good public transport links has led to substantial amounts of forced car ownership, where those who may find it hard to afford to run a car feel they have no other option. ${ }^{15}$ At the same time, investment in pedestrian infrastructure in rural area has been even less than in urban environments: most rural roads lack a pavement and rural pedestrians are often forced to walk on muddy grass verges if they are to avoid traffic. Conditions for walkers on rural highways have changed little since the nineteenth century or earlier, and arguably they have worsened as traffic volumes have increased with serious implications for rural road safety. ${ }^{16}$

The four papers included in this special section of Urban History focus attention on different aspects of walking in urban environments in four different countries in the nineteenth and twentieth centuries. Together they demonstrate the importance of walking as a form of urban transport, its persistence despite the increased availability of alternative forms of transport and the creation of a pedestrian-unfriendly urban environment dominated by motor vehicles, and the degree to which walking was undertaken by all classes and ages, and by both men and women. The four countries (Finland, Sweden, the UK and the USA) are all relatively rich western nations, which went through similar stages of economic and social development, and as such are directly comparable. Because walking is so taken-for-granted it is also largely invisible in many of the sources commonly used to research transport history. Most travel on foot was not officially recorded, and although personal diaries and other accounts can provide important insights into pedestrian behaviour these can only ever be analysed for a small and necessarily unrepresentative portion of the population. ${ }^{17}$ The four papers in this collection have thus needed to find original approaches to their subject matter. Tiina Männistö-Funk makes use of an extensive photographic archive to examine the visibility of pedestrians in the Finnish city of Turku from the 1890s to the 1980s. She focuses especially on the presence of women on the streets of the city, identifies distinctly gendered spaces within the urban

50; T. Försti, 'Gendering the automobile: Men, women and the car in Helsinki, 1900-1930', in The Routledge History Handbook of Gender and the Urban Experience (London, 2017).

${ }^{15}$. J. Shergold and G. Parkhurst, 'Transport-related social exclusion amongst older people in rural Southwest England and Wales', Journal of Rural Studies, 28 (2012), 412-21; A. Ahern and J. Hine, 'Rural transport-valuing the mobility of older people', Research in Transportation Economics, 34 (2012), 27-34.

${ }^{16}$. K. Hamilton and J. Kennedy, Rural Road Safety. A Literature Review (Edinburgh, 2005).

${ }^{17}$. C. Pooley, 'Cities, spaces and movement: everyday experiences of urban travel in England c18401940', Urban History 44(2017), 91-109; C. Pooley, 'Travelling through the city: using life writing to explore individual experiences of urban travel c1840-1940', Mobilities, 12 (2017), 598-609. 
fabric, and demonstrates that in most periods women were more likely than men to be walking through the streets of Turku. The focus of Martin Emanuel's paper is on inter-war Stockholm where he uses a wide range of contemporary reports and newspaper articles to examine the ways in which the city authorities sought to regulate both traffic and pedestrian flows, and the strategies that pedestrians used to navigate and sometimes subvert these structures and regulations. The paper clearly highlights the conflicts that occurred between motor traffic and pedestrians even in the 1920s when by today's standards traffic volumes were low. Colin Pooley makes novel use of the records of London's Central Criminal Court in nineteenth and early-twentieth century England, to explore in detail the characteristics of pedestrians on the streets of London. The streets were crowded with men and women of all ages and from all social classes at most times of the day and night. Walking was the normal means of travel for most people for at least some journeys. Finally, we move to the USA where Peter Norton uses a wide range of contemporary sources to demonstrate that walking persisted throughout the twentieth century, even in what probably was (and still is) the most car-dominated society in the world. He charts persistent attempts to resist the total dominance of cars on city streets, focusing especially on the period 1920 to 1960 . Together, the four papers clearly demonstrate that despite the apparently inexorable rise of automobility in Europe and America, people continued to walk and that pedestrians formed an important if neglected component of urban mobility.

While each of these papers provides important original historical insights into particular periods and places, we suggest that collectively they also have greater resonance. Evidence of the continued practice and significance of walking as a means of everyday transport for most groups of the population also has relevance for present-day transport policies. In a world where active and sustainable forms of transport are needed more urgently than ever due to concerns about global climate change, air pollution, congestion, health and resource depletion among other factors, a reminder of the historical importance of walking in the urban environment may help to refocus attention on the need to actively promote and enable urban walking today. The four papers in this selection arose in part from our participation in a global network on the cultural politics of sustainable urban mobility, ${ }^{18}$ and one of the key aims of this network was to examine ways in which historians could more effectively generate a 'usable past', where knowledge of past patterns,

\footnotetext{
${ }^{18}$. A selection of essays arising from this network will be published as: M. Emanuel, F. Schipper, and R. Oldenziel (eds.) Sustainable Urban Mobility: Histories of Today's Challenge (New York, forthcoming).
} 
processes and behaviours could contribute to present-day transport policies, ${ }^{19}$ including policies in which the promotion of walking as the normal and taken-for-granted means of travel for most short trips in urban areas is a central focus. In the past walking was normal for most people and there is no reason why this should not be the case today.

We hope that these four papers will not only stimulate further historical research on the neglected topic of everyday walking but also will encourage fresh approaches to the study of the city. Good data on how pedestrian practices changed over time is very hard to come by as available evidence is rarely directly comparable. The papers do demonstrate that the experience of the pedestrian on city streets was often dependent on changes in other road users and the policies that were put in place to accommodate new forms of transport. It can be suggested, for instance, that through much of the nineteenth century those who walked dominated urban space and thus city authorities had little need to plan for pedestrians or to consider them as a distinct transport mode. As various forms of wheeled transport increased in number and size, and especially following the introduction of powered (as opposed to horse drawn) transport, the separation of pedestrians from other traffic was increasingly seen as important both to allow the free flow of wheeled traffic and for the safety of pedestrians. In this way those who walked were increasingly marginalised and they became a relatively neglected mode of travel in planning and policy documents. People did still walk, often in large numbers, but they became increasingly invisible in transport policy documents. Most recently walking has increasingly been viewed as an important travel mode in urban areas, driven by the need to reduce pollution and congestion and improve public health, but real gains have been slow to occur. What is also clear from the papers in this collection is that walking was common for both men and women in the cities studied, that pedestrian practices were highly variable, and that those who walked were skilled at negotiating the urban environment. There were many different manifestations of the pedestrian and multiple responses to the urban environment. These could vary in relation to a wide range of factors, including the time of day, weather conditions, companions, location and the purpose of the journey. It is this diversity and ubiquity that makes a focus on the pedestrian a particularly useful approach to urban history.

${ }^{19}$. See also C. Divall, 'Transport history, the usable past and the future of mobility', in M. Grieco and J. Urry (eds.), Mobilities: New perspectives on Transport and Society (Farnham, 2011), 305-319; C. Divall, J. Hine and C. Pooley (eds.), Transport Policy: Learning Lessons from History (Farnham, 2016). 